\title{
Holistic approach to the ecological cargo distribution in urban areas with the use of multi-modal transport
}

\author{
M. Jacyna \& E. Szczepański \\ Faculty of Transport, Warsaw University of Technology, Poland
}

\begin{abstract}
Due to the continuous development of cities and growing demand for cargo transportation, it is necessary to develop and implement new concepts for distribution. The paper presents the concept of a hierarchical cargo distribution in the distribution system using multi-modal transport. This approach involves the use of trams and electric vehicles. It is justified from the point of view of the European Union's strategy related to lowering emissions of toxic compounds. The use of such means of transport not only has a positive impact on the ecology, but also on the social development of cities and the living conditions of the inhabitants. The presented concept includes the use of cargo consolidation centers located on the outskirts of cities. The city was divided into three zones with different traffic characteristics and the possibility of dynamically change the areas size occupied by them. The use of different means of transport needed to take account of appropriate transport infrastructure like sidings (loading track) located within the city. This article presents a mathematical model of that distribution system. Linear and point infrastructure and other system components like means of transport were characterized. Constraints arising from the technical and legal conditions were identified. The considerations presented in this article represent an interesting approach to deliveries in urban areas. Positive and negative aspects of the used approach were presented in the paper.

The developed concept is a new approach to the cargo distribution with a positive impact on reducing exhaust emissions in cities. Article presents the part of research in the "EMITRANSYS" project implemented by the Faculty of Transport in Warsaw University of Technology and the Poznan University of Technology.

Keywords: multi-modal transport in urban areas, cargo tram, ecological distribution system, model of multistage distribution system, EMITRANSYS.
\end{abstract}




\section{Introduction}

Transportation of goods in urban areas has a significant impact on the efficiency of the economy, quality and attractiveness of life, as well as the development of the local community. Currently to these issues is given less attention than passenger transport, but can be seen growing interest in the problems generated by the transport of goods in urban areas [1-3].

Transportation of goods is on the one hand the main factor enabling development of most economic and social activities taking place in urban areas, which is associated with the supply of shops and places of work and recreation, and waste management. On the other hand, freight transport is a major factor (traffic jams) that hinders the social life of citizens. It is therefore necessary to seek solutions to reduce freight traffic in urban areas. One of such solution is the city logistics, which aims to reduce the burden associated with the transportation of goods in urban areas and supporting economic and social development of cities $[4,5]$.

The main objective of logistics service is primarily to reduce high-volume traffic in cities. This also reduces congestion, pollution and increase traffic safety. Such an effect can be achieved through effective transport planning and increase the use of means of transport and minimizing the length of the delivery route [6]. This issue is connected with distribution of products dedicated to the planning, organization and control of the placement of products on the market to make them available for sale. Meeting the transportation needs in a given area through the implementation of the transport process is the main objective of the distribution. Due to the continuous development of cities and growing demand for transport is justified to search for new solutions to improve customer service. Improvement should be implemented not only in terms of the cost of the order, but also from the point of view of the transport quality and ecology [7].

The use of cargo trams can be an interesting solution of the problem. Cargo tram in distribution is a great alternative for the supply of goods to the customers demanding just-in-time deliveries. This solution can reduce the impact of congestion on delivery time However, such solution face a number of problems associated with poorly developed infrastructure, the need to implement an expensive investment, problems with traffic separation on tram network, as well as the difficulties in estimating costs and benefits. However, we can highlight the positive aspects of reducing congestion, improving road safety, reducing emission of toxic compounds and noise $[8,9]$.

\section{Cargo trams deliveries in urban areas}

The use of trams to cargo transport in urban areas is a relatively innovative approach, which is reluctant to apply because of the costs difficult to estimate of such a project. The continuous development of the automotive industry and new solutions used for trucks and vans reduce interest in rail transport. Despite the difficulties in the use of multi-modal approach to urban freight transport, it is 
gaining their followers. In Europe, there are several examples of the use of trams to transport cargo $[1,10]$.

A pioneer in the use of cargo trams in Europe is Germany. Volkswagen uses them for private purposes, the supply of production. Main objective of the project implementation was to reduce heavy road transport required for supplies the production in the famous factory Gäsernen VolkswagenManufaktur [8].

Zurich authorities decided to return to the concept of using the cargo tram due to significant problems with the waste disposal. In 2003, a freight tram lines in Zurich were restored. The proposed solution has gained broad support of society, so authorities decided to extend the offer. The reason for the great interest of citizens is that improving the living conditions what mean reducing traffic of standard garbage and the service is offered free of charge for Zurich citizens $[8,10]$.

Austria is another country where the concept of using cargo tram was not completely ignored. The experience drawn from Dresden and Zurich led communication companies in Vienna to create their own project called GüterBim. According to the assumptions GüterBim had to run between 3 large logistics centers delivering cargo to customers located in the urban area. The one of the most important problems is the fact that it is not possible to completely eliminate road vehicle traffic and lack of translate environmental benefits to business decisions [11].

Amsterdam considering the implementation cargo transportation using trams, but after the test program further work was suspended [10]. A comparison of sample solutions using trams to transport cargo in urban areas is shown in Table 1 .

Table 1: $\quad$ Comparison of solutions with cargo trams in Europe.

\begin{tabular}{|c|c|c|c|}
\hline \multirow[b]{2}{*}{ Parameter } & \multicolumn{3}{|c|}{ Cargo Tram in Europe } \\
\hline & Dresden & Zurich & Vienna \\
\hline Project name & CarGoTram & Cargo Tram & GüterBim \\
\hline Implementation date & 2001 & 2003 & 2005 \\
\hline Is still functioning? & yes & yes & no \\
\hline $\begin{array}{l}\text { Estimated cost of } \\
\text { implementation }\end{array}$ & about $4.3 \mathrm{mln} €$ & about $32,000 €$ & 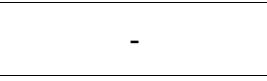 \\
\hline Routes & $\begin{array}{l}\text { route about } 4.5 \mathrm{~km} \\
\text { (from warehouses to } \\
\text { the factory VW) }\end{array}$ & $\begin{array}{c}9 \text { different routes for } \\
\text { waste collection }\end{array}$ & $\begin{array}{l}\text { Routes from } 3 \text { large } \\
\text { Logistics Centers } \\
\text { (covering the whole } \\
\text { city) }\end{array}$ \\
\hline $\begin{array}{l}\text { Type of the } \\
\text { composition }\end{array}$ & $\begin{array}{l}\text { A five-partial, two- } \\
\text { way }\end{array}$ & $\begin{array}{c}\text { A three-partial, one- } \\
\text { way }\end{array}$ & $\begin{array}{l}\text { A two-partial, one- } \\
\text { way }\end{array}$ \\
\hline Number of cars & 5 & 3 & 2 \\
\hline Capacity & $60 \mathrm{t} / 214 \mathrm{~m}^{3}$ & ok. $12 \mathrm{t} / 48 \mathrm{~m}^{3}$ & Ok. $13 / 40 \mathrm{~m}^{3}$ \\
\hline Length & about $60 \mathrm{~m}$ & about $18 \mathrm{~m}$ & about $19 \mathrm{~m}$ \\
\hline Width & $2.2 \mathrm{~m}$ & $2.2 \mathrm{~m}$ & $1.5 \mathrm{~m}$ \\
\hline
\end{tabular}

Source: own developed based on [1, 9-11]. 
The need to provide solutions in tram transport for other than passengers is due to the fact that there are different specifications of this type of movement. The differences result directly from the need for isolating the passenger and cargo transport. Isolation necessary was mainly related to the two different types of transport operating parameters [9]. The most important are:

- time stops during unloading (long for cargo trams, short for passenger),

- speed, acceleration and deceleration.

Due to the low prevalence of cargo tram is a solution, which to this day is still controversial. The biggest disadvantage of using cargo trams for distribution is that there are substantial investments required for the implementation. Such investments should be considered for long periods of time because it is long-term returns. Assuming the size of present flows stability, and even their growth and rising fuel prices, this solution has the opportunity to bring significant benefits to both private companies and municipalities. An important problem is the tram network and its density in different regions of the city. Therefore, there is a need to use road vehicles to ensure the distribution. Thus, environmental and economic benefits are not entirely satisfactory [12].

A very important issue is the separation of freight and passenger traffic needed. The distinction is due to the operational parameters of the two different types of tram depots. Therefore, one option is to conduct deliveries on the tram network only at night and off-peak periods. Way of tram moving is also important issue. Movement of a cargo tram on the common track with a passenger tram is exposed to downtime caused, for example, by an accident or vehicle failure. Due to the different degree of density and expand the tram network should be assumed that such cases can be seriously risking the elimination of this concept [8].

Despite some major disadvantages in the use of cargo trams it also has many advantages. The first of these is primarily a significant reduction of vans and trucks traffic in the cities. Despite the dispersion of destination points within the city, and thus the need to use road vehicles can be significantly reduced their runs to a minimum. Therefore the transport system based on freight trams phenomenon significantly reduces congestion in urban areas. Referring to the environmental aspects can be relied to Dresden example. Each of the trucks which traffic is replaced by the movement of cargo tram does not emit toxic compounds such as nitrogen oxides, carbon dioxide, etc. Moreover, it is important to reduce the noise caused by the high volume of trucks and vans traffic [10].

\section{The concept of multistage distribution system in urban agglomeration}

Holistic consideration of distribution problems requires consideration of many factors and the relationship between them [2]. In order to apply the system approach assumes that in the urban areas distribution system will be located:

- Cargo Consolidation centers located on the outskirts of the city, which provides services such as order picking and storage of cargo $-\boldsymbol{O}$; 
- Intermediate points or tramway sidings where transshipment from trams on vans will be executed $-\boldsymbol{S}$;

- Destination points located in various areas of the city, which can be stores whether service points $-\boldsymbol{D}$.

The concept of multistage distribution systems is not a new concept and was raised, among others in article Jacyna [13]. Novelty presented in the paper is the use of trams where the operating area is dynamically adapted to the needs and conditions in the transportation network. Terms and demand is determined on the network nodes and arcs. Elements of point infrastructure were defined, i.e. Cargo Consolidation Centers (CCC) as a set $\boldsymbol{O}=\{o: o=1,2, \ldots, \bar{O}\}$, where: $o-$ number of $o$-th $\mathrm{CCC}, \bar{O}-\mathrm{CCC}$ in total; siding tracks as a set $\boldsymbol{S}=\{s: s=\bar{O}+1, \bar{O}+2, \ldots, \bar{O}+\bar{S}\}$, where: $s$ - number of $s$-th transshipment point, $\bar{S}$ - siding tracks in total; Destination points (Recipients) as a set $\boldsymbol{D}=\{d: \quad d=\bar{O}+\bar{S}+1, \bar{O}+\bar{S}+2, \ldots, \bar{O}+\bar{S}+\bar{D}\}$, where: $d-$ number of $d$-th destination point; $\bar{D}$ - destination points in total. In the paper the connection point between the infrastructure is defined, such as the tram connection between CCC and siding track $-\boldsymbol{L}^{o s}=\{(o, s): o \in \boldsymbol{O}, s \in \boldsymbol{S}\}$, road connection between siding track and Destination points $\boldsymbol{L}^{s d}=\{(s, d): s \in \boldsymbol{S}, d \in \boldsymbol{D}\}$, Road connection between Destination points $\boldsymbol{L}^{d d^{\prime}}=\left\{\left(d, d^{\prime}\right): d \in \boldsymbol{D}, d^{\prime} \in \boldsymbol{D}, d \neq d^{\prime}\right\}$ and road connection between CCC and Destination points $\boldsymbol{L}^{o d}=\{(o, d): o \in \boldsymbol{O}, d \in \boldsymbol{D}\}$ using to direct transport. Moreover, means of transport are defined. Set of types of road vehicles $\boldsymbol{V}=\{v: v=1,2, \ldots, \bar{V}\}$ where $v$-number of $v$-th road vehicle type, $\bar{V}$ - road vehicle types in total. Any type of road vehicle is characterized by a capacity $q(v)$. Set of cargo tram types $\boldsymbol{B}=\{b: b=1,2, \ldots, \bar{B}\}$, where $b-$ number of $b$-th cargo, $\bar{B}$ - cargo tram types in total tram type. Any type of cargo tram is characterized by a capacity $q(b)$.

The concept of the city transport system model using multi-modal transport (trams + vans) is an attempt to introduce an approach to streamline the process of cargo distribution, and also preferably affecting the reduction of exhaust emissions and noise.

Tram in the case of multistage distribution system will be held a role of cargo freight between Cargo Consolidation Center (CCC) and transshipment points located in the central part of the city. Capabilities of a cargo tram in distribution depends on the number of transshipment points (siding tracks) and their placement on the city tram network. This concept assumes that the distance of transportation, using the tram and appropriate siding tracks will change dynamically depending on the demand and current operating conditions on the 
transport network. However, it will depend on the results of calculations and decisions in the transport task [14,15]. Concept is schematically shown in Fig .1

In the model, the city was divided into three zones depending on the relation of transport (CCC-recipient) occurring in the transport task. The first zone is the outer zone, where to cargo distribution is using road transport -direct transport (CCC-recipient), as well as tram and road transport (CCC-Siding track (zone $\left.2^{\text {nd }}\right)$-recipient). The second zone is the middle zone, where the transport take place only with trams and here are located siding tracks used in transportation process; the area of this zone is dynamic. Vans pick up cargo from siding track and deliver it to recipients in zone 1,2 and $3^{\text {rd }}$. Inner zone (zone $3^{\text {rd }}$ ), in which is no possibility of tram infrastructure development and cargo transport can be carried out using only vans [16].

Determination of the delivery schedule in such distribution system is a complex process and requires consideration of many factors such as: time windows, frequency of trams and traffic. It is important to also take into account traffic at certain intervals throughout the day.

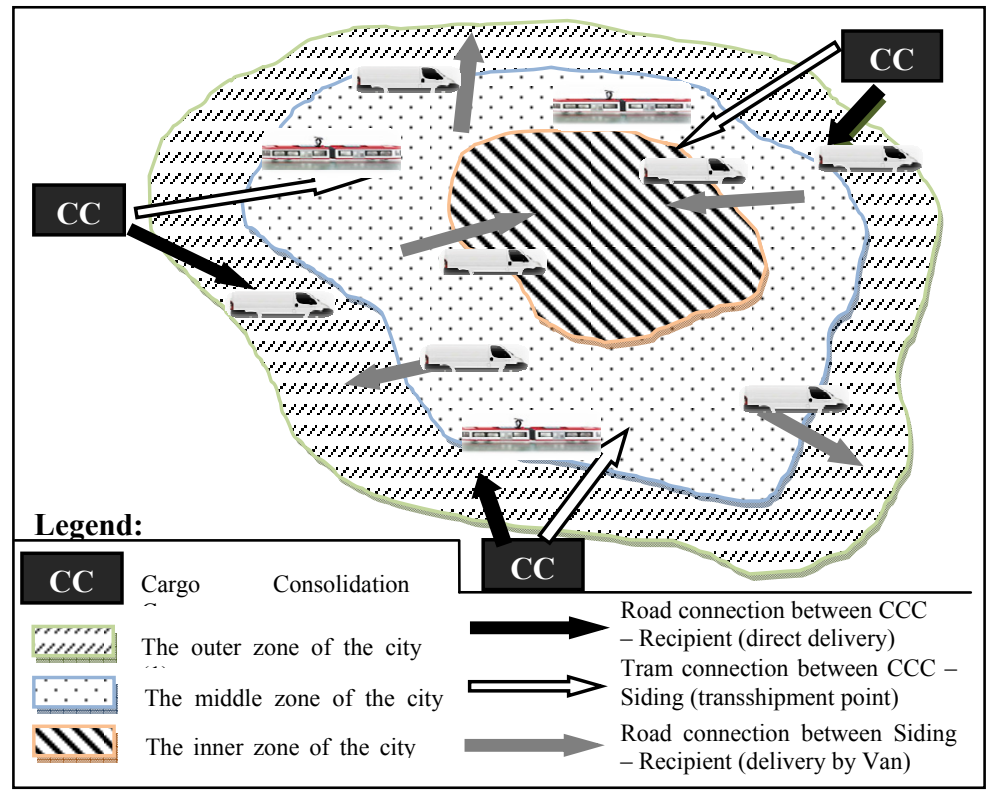

Figure 1: Concept of using trams in the multistage distribution system.

\section{Mathematical problem record}

For the purpose of model building it was necessary to define the structure of the transport network. The transport network is described by a graph $\boldsymbol{G}=(\boldsymbol{V}, \boldsymbol{E})$ and consists of vertices $(\boldsymbol{V})$ - Cargo Consolidation Centres, Destination points (Recipients), as well as siding tracks (transshipments points). This network also 
includes $(\boldsymbol{E})$ edges between the vertices (road and rail connections) [3]. A graph structure of the distribution system in the analyzed issues is presented in Fig. 2.

Formulated task is a modified Multiple Traveling Salesman Problem (MTSP). In the case of modification, there are additional limitations, for example: vehicle capacity or time windows in individual recipients [17].

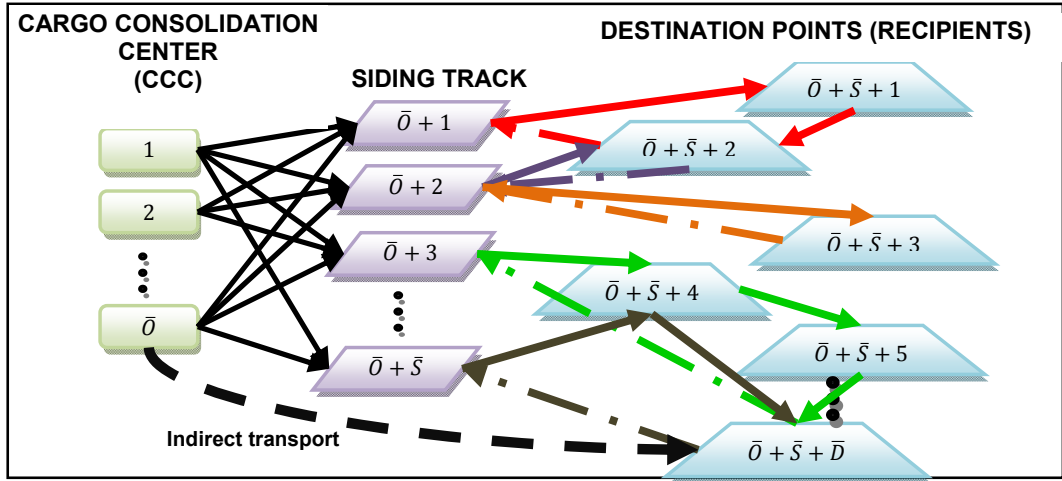

Figure 2: Graph structure of distribution system.

In order to provide a mathematical model of multistage distribution system with the use of trams to service recipients located in urban areas, it is necessary to specify the input data, decision variables, constraints, and function criteria.

In the problem the values of decision variables should be designated:

\begin{tabular}{l|l}
\hline Data & \multicolumn{1}{|c}{ Description } \\
\hline$x_{o s}^{b}$ & $\begin{array}{l}\text { the volume of traffic using } b \text {-th type of vehicle between } o \text {-th CCC and } s \text { - } \\
\text { th siding track }\end{array}$ \\
\hline$x_{o d}^{v}$ & $\begin{array}{l}\text { the volume of traffic using } v \text {-th type of vehicle between } o \text {-th CCC and } d \text { - } \\
\text { th destination point (recipient) }\end{array}$ \\
\hline$x_{s d}^{v, h}$ & $\begin{array}{l}\text { The volume of traffic using } v \text {-th type of vehicle, during } \\
h \text {-th run between } s \text {-th siding track and } d \text {-th destination point (recipient) }\end{array}$ \\
\hline$x_{d d^{\prime}}^{v, h}$ & $\begin{array}{l}\text { The volume of traffic using } v \text {-th type of vehicle, during } \\
h \text {-th run between } d \text {-th destination point and } d \text { '-th destination point } \\
\text { (recipient) }\end{array}$ \\
\hline$y_{d^{\prime} s}^{h}$ & $\begin{array}{l}\text { binary variables determining the existence of a connection between } d \text { '-th } \\
\text { destination point (recipient) and } s \text {-th siding track during } h \text {-th run }\end{array}$ \\
\hline$y_{d}$ & $\begin{array}{l}\text { binary variables defining the handle or not handle } d \text {-th destination point } \\
\text { (recipient) }\end{array}$ \\
\hline
\end{tabular}

that the total cost of the distribution task

$$
\begin{gathered}
\mathrm{F}(\boldsymbol{X} 1, \boldsymbol{X} 2, \boldsymbol{X} 3, \boldsymbol{X} 4, \boldsymbol{Y} 1, \boldsymbol{Y} 2)=\sum_{b \in \boldsymbol{B} o \in \boldsymbol{O}} \sum_{s \in \boldsymbol{S}} x_{o s}^{b} d m_{o s} c_{1}(\mathrm{~b}, o, s) \\
+\sum_{v \in \boldsymbol{V}} \sum_{o \in \boldsymbol{O}} \sum_{d \in \boldsymbol{D}} x_{o d}^{v} d m_{o d} c_{2}(v, o, d)+\sum_{d \in \boldsymbol{D}}\left[y_{d} c_{4}(d)\right]+
\end{gathered}
$$




$$
\begin{gathered}
+\sum_{v \in V}\left\{\sum_{h \in \boldsymbol{H}}\left[\left(\sum_{s \in \boldsymbol{S}} \sum_{d \in \boldsymbol{D}} \operatorname{sgn}\left(x_{s d}^{v, h}\right) d m_{s d}+\sum_{d \in \boldsymbol{D}} \sum_{d^{\prime} \in \boldsymbol{D}} \operatorname{sgn}\left(x_{d d^{\prime}}^{v, h}\right) d m_{d d^{\prime}}+\sum_{d^{\prime} \in \boldsymbol{D}} \sum_{s \in \boldsymbol{S}} y_{d^{\prime} s}^{v, h} d m_{o^{\prime} s}\right)\right] c_{3}(v)\right\}+ \\
+\bar{H} \cdot k s \rightarrow \min
\end{gathered}
$$

should be minimal.

\begin{tabular}{|c|c|}
\hline Data & Description \\
\hline$G=\langle\boldsymbol{V}, \boldsymbol{E}\rangle$ & graph of transportation network structure \\
\hline $\boldsymbol{N}=\left[n_{d}\right]$ & recipients (destination points) demand matrix \\
\hline $\mathbf{D M 1}=\left[d m_{d s}\right]$ & distance matrix between $o$-th CCC and $s$-th siding track \\
\hline $\mathbf{D M 2}=\left[d m_{o d}\right]$ & distance matrix between $o$-th CCC and $d$-th recipient \\
\hline $\mathbf{D M 3}=\left[d m_{s d}\right]$ & distance matrix between $s$-th siding track and $d$-th recipient \\
\hline $\mathbf{D M 4}=\left[d m_{d d \prime}\right.$ & distance matrix between $d$-th and $d$ '-th recipient \\
\hline $\mathbf{D M 5}=\left[d m_{d^{\prime} s}\right]$ & distance matrix between $d^{\prime}$-th recipient and $s$-th siding track \\
\hline$k s$ & cost of h-th run realization from siding track to recipient \\
\hline$c_{1}(b, o, s)$ & $\begin{array}{l}\text { cost of transport } 1 \text { cargo unit at a distance of } 1 \mathrm{~km} \text { between } \\
\text { CCC and siding with the } b \text {-type of tram }\end{array}$ \\
\hline$c_{2}(v, o, d)$ & $\begin{array}{l}\text { cost of transport } 1 \text { cargo unit at a distance of } 1 \mathrm{~km} \text { between } \\
\text { CCC and recipient with the } v \text {-type of vehicle (indirect) }\end{array}$ \\
\hline$c_{3}(v)$ & cost of $1 \mathrm{~km}$ journey by $v$-th vehicle type \\
\hline$c_{4}(d)$ & penalty for not handle $d$-th recipient \\
\hline$q(v)$ & road vehicle capacity \\
\hline$q(b)$ & rail vehicle capacity \\
\hline $\begin{array}{l}\boldsymbol{H}=[h: h \\
=1,2, \ldots, \bar{H}]\end{array}$ & $\begin{array}{l}\text { set } H \text { and number of runs }-\bar{H} \text { (determined in the } \\
\text { optimization process) }\end{array}$ \\
\hline
\end{tabular}

For a such optimization task input data should be considered:

\section{and solution should satisfy constraints (for example):}

- volume of cargo transported from CCC to side track should be equal to volume of cargo transported from side track to recipient;

- volume of cargo transported from CCC cannot be higher than demand of recipients;

- capacity of $v$-th type vehicle on $h$-th run cannot be exceeded;

- vehicle leaving $s$-th siding must return to it;

- vehicle during the $h$-th run visiting $d$-th recipient only once;

- delivery must take place within the prescribed time windows;

- separation of cargo traffic from passenger on tram lines must be taken into account.

This model provides an overview of the problem. During its solving must be recognized much more data and constraints taking into account the randomness and the time dependence of customer service [3, 18]. In 5 points, the paper presents the first stages of work on the problem of delivery with the use of trams using a pre-made application "TramTrans". 


\section{Solving the problem of distribution in urban areas with the use of cargo trams}

Model of cargo distribution in urban areas was implemented in the form of a computer program. The "TramTrans" is an application that assists the user in decision-making process in determining rational transportation plan. The purpose of the application is to determine transportation plan for a metropolitan area, so that the total cost of transport to be as minimal as possible. Costs are calculated based on data taken from the database properly prepared. In the application major role plays a genetic algorithm. Search for solutions using this type of algorithm consist three main procedures: randomly generation of initial population, crossover and mutations. The overall scheme is shown in Fig. 3.

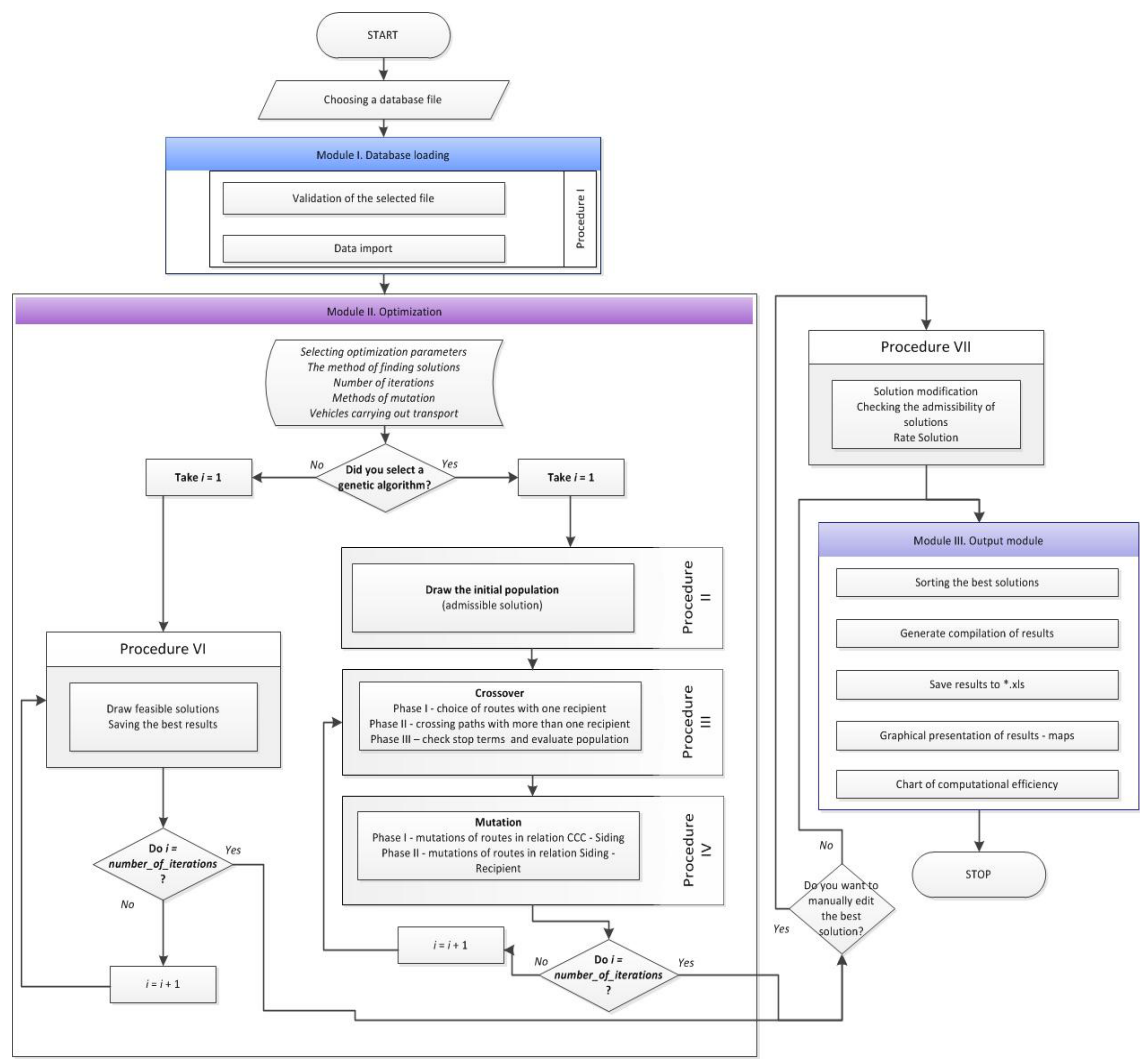

Figure 3: Diagram of the "TramTrans" algorithm.

Randomly generation of initial population procedure is used to determine the initial population represents a feasible solution. An important element of algorithm is an individual chromosome. First gene responsible for the number of $\mathrm{CCC}$, the second and the last number represents the $s$-th siding, the genes located 
between the siding tracks genes are identified as genes represent recipients visited in the one route. Another element of the genetic algorithm is a crossover. It is one of the most important elements. It is responsible for improving the designated sequence of solutions, but cannot be done completely randomly. To create a child population crosses the best parents. In implementation Pittsburg approach was used. That approach means that rules for each of the individuals working together to achieve the best evaluation value for the whole population. The method consists in replacing the crossing paths of genes for individuals which the number of recipients is greater than 1 . Other individuals representing the direct delivery subject only to the mutation. Mutation is another important mechanism in terms of solution search precision. In this way the operator can change the genes of one individual. The algorithm uses two types of mutation operators. First type is dedicated to gens which represents CCC-Siding relation. It is based on conversion of gen number for CCC or siding. However, the mutation of relation recipient-recipient is based on a randomly change of the gen location. Further genes as a result of this operation, move up one place.

Using pre-designed and developed application "TramTrans" sample calculations were performed for Warsaw (Poland). Cargo Consolidation Centers were located on the outskirts of cargo consolidation centers. In the central zone of the city located siding track where delivery charge is from CCC by trams. In Warsaw identified 30 customers from different industries and different needs. In order to perform the calculations the database according to the model presented in section 4 was prepared. The use of application gave results encouraging to further work on the "TramTrans" and on the model. In figure 4 the values of the criterion function according to the number of iterations performed are shown. On this basis it can be concluded that the program performs its functions and contributes to the improvement of found solutions.

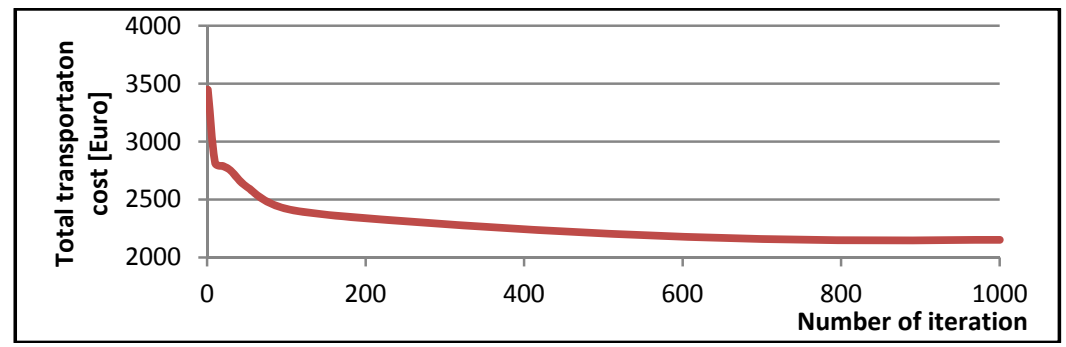

Figure 4: Chart of solution search effectiveness.

\section{Conclusion}

Model of multistage distribution system with trams described in this article is an interesting concept to supply in urban areas. The calculations and results are preliminary attempt to solve the problem. In further stages of the model and its implementation in the form of computer applications will be developed and 
improved. Full survey results with algorithms and calculations will be presented in future articles.

However, the proposed solution with trams put serious doubts as to its effectiveness. The use of such a solution in the cities certainly reduces congestion and does not emit as much pollution as road transport. As noted earlier it is impossible to completely eliminate the use of road transport, but can be significantly reduced. The main problem is the profitability of the project (and the difficulty in estimating the costs and benefits). Due to the continuous development of the automotive industry, modern vehicles emit less harmful compounds, and this reduces the interest in such solutions. As shown in figure 5 the structure of vehicles in terms of categories issue is at a good level and as indicated (Boguś and Merkisz [19]) will be subject to a significant improvement.

It is worth looking for and implementing solutions based on other means of transport. As indicated in figure 5, pollution emitted by trucks is at a very high level, to be added to the congestion, noise, accidents, and the mood of the local community. Using the freight trams can significantly affect the various problems encountered in the transport of goods in cities.

Summing up the considerations in the article shows that it is worth looking for new solutions, improve existing ones and try to implement them in reality [4]. Any even small environmental measures are reasonable and necessary [6]. The discussion is a prelude to further work on the model of the distribution system using trams stores. In the later research model will be developed and simulations will be carried out in the application for the city of Warsaw (Poland).

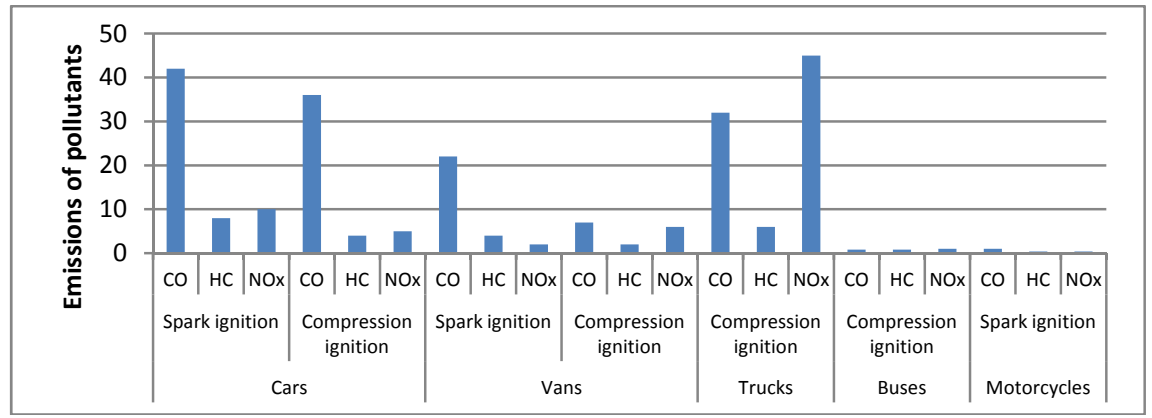

Figure 5: Emissions of toxic compounds in relation to the vehicle category (research for the Poznan agglomeration) [19].

\section{Acknowledgement}

This paper was prepared as a part of the research project "Proecological transport system designing" (EMITRANSYS) funded by the National Centre for Research and Development. 


\section{References}

[1] Alessandrini A., Delle Site P., Filippi F., Salucci M. V.: Using rail to make urban freight distribution more sustainable. European Transport, Issue 50 2012.

[2] Bluszcz M., Jacyna M.: Model solution of connections between urban logistic system and national logistic system. Archives of Transport, Warsaw 2009.

[3] Jachimowski R., Zak J.: Vehicle Routing Problem with Heterogeneous Customers Demand and External Transportation Costs. Journal of Traffic and Logistics Engineering, vol.1, no.1, pp. 46-50, March 2013.

[4] Lindholm M.: A sustainable perspective on urban freight transport: Factors affecting local authorities in the planning procedures. 6th International Conference on City Logistics, Puerto Vallarta, Mexico, Jun 30-Jul 02, 2009.

[5] Quak, H. J., de Koster, M. B. M.: Delivering Goods in Urban Areas: How to Deal with Urban Policy Restrictions and the Environment. 4th International Workshop on Freight Transportation and Logistics, Cesme, Turkey, vol. 43, Issue 2, pp. 211-227, May 2009.

[6] Karen L.: Transport and social exclusion: Where are we now? Transport Policy, vol. 20, pp. 105-113, March 2012.

[7] Crainic T. G., Ricciardi N., Storchi G.: Advanced freight transportation systems for congested urban areas. Transportation Research Part C: Emerging Technologies, vol. 12, Issue 2, pp. 119-137, April 2004.

[8] Molecki B., Lewandowski K.: Tramway freight transport in towns. Transport Miejski i Regionalny 2005, nr 9, pp. 24-31, 2005.

[9] Szymczak M.: Wykorzystanie transportu szynowego do przewozu towarów $w$ mieście. Zeszyty Naukowe WSHiU, vol. 10, pp. 45, 2005.

[10] Dembińska-Cyran I.: Zastosowanie tramwaju transportowego $w$ obstudze dostaw na obszarze miasta. LogForum, 6/2005.

[11] Poliński, J.: Rola tramwaju towarowego w ograniczeniu wykorzystywania TIR-ów zaopatrujących duże miasta. Problemy Kolejnictwa, vol. 146, pp. 53-64, 2008.

[12] Regue R., Bristow A. L.: Appraising Freight Tram Schemes: A Case Study of Barcelona. European Journal of Transport and Infrastructure Research, vol. 13, Issue 1, pp. 56-78, Jan 22, 2013.

[13] Jacyna M.: The role of Cargo Consolidation Center in urban logistic system. Urban Transport XII, WIT Press 2011.

[14] Jacyna M., et al.: The Logistic System of Poland and Transport Comodality. Warsaw University of Technology Publishing House, Warsaw 2011.

[15] Pyza D.: Transport service of a cargo consolidation centre with respect to logistics service of urban agglomerations. 17th International Conference on Urban Transport and the Environment, Pisa, Italy, May 2011.

[16] Jacyna M., Kłodawski M.: Model of transportation network development in aspect of transport comodality. Proceedings of the $21 \mathrm{st}$ International 
Conference on Systems Engineering ICSEng 2011, Las Vegas, Nevada USA.

[17] Quak, H. J., de Koster, M. B. M.: Delivering Goods in Urban Areas: How to Deal with Urban Policy Restrictions and the Environment. 4th International Workshop on Freight Transportation and Logistics, Cesme, Turkey, vol. 43, Issue 2, pp. 211-227, May 2009.

[18] Munuzuri J., Cortes P., Onieva L.: Modelling peak-hour urban freight movements with limited data availability. Computers \& Industrial Engineering, vol. 59, Issue 1, pp. 34-44, Aug 2010.

[19] Boguś P., Merkisz J.: Misfire detection of locomotive diesel engine by nonlinear analysis. Mechanical Systems and Signal Processing, vol. 19, Issue 4, pp. 881-899, July 2005. 